\title{
Morphological variation in a natural population of Drosophila mediopunctata: altitudinal cline, temporal changes and influence of chromosome inversions
}

\author{
BLANCHE C. BITNER-MATHE**, ALEXANDRE A. PEIXOTO \& LOUIS B. KLACZKO† \\ Departamento de Genética, Instituto de Biologia, Universidade Federal do Rio de Janeiro and $\uparrow$ Departamento de \\ Genética e Evolução, Instituto de Biologia, Universidade Estadual de Campinas, São Paulo, Brazil.
}

\begin{abstract}
To characterize the morphological variation in a natural population of Drosophila mediopunctata, males were collected on three occasions at a single locality. From each wild-caught male 14 body measures were taken and the karyotype for inversions on chromosomes $\mathrm{X}$ and II was determined. Through a principal components analysis, two sources of variation, identified as size and shape, accounted for approximately 80 and 6 per cent of the total morphological variability, respectively. The shape component was determined primarily by variations in the position of the wing second longitudinal vein. Differences between collections were detected both for size and shape. An altitudinal cline was observed in respect of wing shape, although altitude explained only a small part of the shape variation. Size and shape were affected by chromosome II inversions. However, in respect of size, no direct differences were detected between karyotypes but a significant interaction between collecting date and karyotype was found. This suggests that karyotypes might differ in their norms of reaction in the field.
\end{abstract}

Keywords: chromosome inversions, clines, Drosophila mediopunctata, morphometry, principal components, reaction norm, wing morphology.

\section{Introduction}

Chromosome inversion polymorphisms in Drosophila are frequently maintained by selection and it is generally assumed that inversions represent coadapted gene complexes (Sperlich \& Pfriem, 1986; Krimbas \& Powell, 1992). Similarly, morphology is also viewed as the result of a complex and integrated system. Organisms are not mere collections of isolated traits, but the results of genetic, environmental and developmental constraints (Maynard Smith et al., 1985; Price \& Langen, 1992).

One approach to the study of integration at the morphological level is through the use of multivariate techniques to try to characterize variations in size and shape. The principal components analysis is a method that allows one to summarize the information of many correlated measures, extracting, through their linear combination, new latent variables. With morphological measurements, the first two components usually

*Correspondence. Present address: Departamento de Biologia, Instituto de Biociências, Universidade de São Paulo, Caixa Postal 11461, 05422-970, São Paulo - SP, Brazil. account for most of the variation present in the original data. The first principal component (PC1) is normally correlated positively with each measurement, indicating that it can be interpreted as an estimate of 'general size'. The second principal component ( $\mathrm{PC} 2)$ is usually a contrast between different measurements, indicating variations in shape (Marcus, 1990).

In Drosophila, morphological studies are, generally, limited to a few characters analysed independently. The presence of genetic variation in individual morphological traits within and between populations which are subject to temporal and spatial changes in their environment, has been demonstrated many times (Prevosti, 1955; Misra \& Reeve, 1964; David \& Bocquet, 1975; Pfriem, 1983; Coyne \& Beecham, 1987; Prout \& Barker, 1989; Imasheva et al., 1994). However, studies that have considered several characters simultaneously are very rare (Stalker \& Carson, 1947, 1948, 1949; Misra, 1966). To our knowledge, no investigation has been published using several measurements to analyse variations in general size and shape among individuals taken directly from a natural population of Drosophila. 
The hypothesis that chromosome inversions and morphology may be correlated was first proposed by Stalker \& Carson (1947). Since then, a number of studies - using only one or two body measurements-have shown significant effects of chromosome inversions on morphological traits (Matzke \& Druger, 1976; Garcia-Vazques \& SanchezRefusta, 1989; Ruiz et al., 1991; Hasson et al., 1992). In some cases, however, no correlation was detected (Sokoloff, 1965).

Peixoto \& Klaczko (1991) described inversion polymorphisms involving the chromosomes $\mathrm{X}$ and II in a natural population of Drosophila mediopunctata from Parque Nacional do Itatiaia in the states of Rio de Janeiro and Minas Gerais, Brazil. On the second chromosome they observed nine gene arrangements in the distal region $(D A, D I, D P, D S$, etc.) and nine in the proximal region $(P A O, P B O, P C O$, etc. ). There is a strong linkage disequilibrium between the inversions in these regions. The most common haplotypes in this population are $D A-P A O, D I-P B O$ and $D S-P C O$ (Table 1). An altitudinal cline and seasonal changes in these haplotype frequencies were observed (Peixoto \& Klaczko, 1988).

The present report describes, in this same natural population, variations in size and shape assessed by unifactorial and multifactorial techniques. Variations along an altitudinal gradient and throughout the year were analysed. We also investigated the effect of chromosome II and $\mathrm{X}$ inversion karyotypes on morphology.

\section{Materials and methods}

The collections on which the present study is based were made in Parque Nacional do Itatiaia. This park

Table 1 Frequency by months of the chromosome II haplotypes in a natural population of Drosophila mediopunctata from Parque Nacional do Itatiaia

\begin{tabular}{lrrr}
\hline Haplotype & August & March & November \\
\hline$D A-P A O$ & 53.5 & 43.9 & 44.0 \\
$D I-P B O$ & 18.5 & 15.8 & 19.8 \\
$D P-P C O$ & 5.8 & 12.3 & 11.2 \\
$D S-P C O$ & 9.6 & 14.0 & 11.2 \\
$D V-P C O$ & 2.7 & 2.6 & 5.2 \\
$D T-P C 1$ & 2.7 & 2.6 & 1.7 \\
$D A-P A 8$ & 0.8 & 0.0 & 0.9 \\
$D A-P B O$ & 0.8 & 2.6 & 2.6 \\
$D I-P A O$ & 0.4 & 0.0 & 0.9 \\
Others & 5.4 & 6.1 & 2.6 \\
$2 n$ & 260 & 114 & 116 \\
\hline
\end{tabular}

Figures are percentages. stands on the slopes of the Serra da Mantiqueira $\left(22^{\circ} 25^{\prime} \mathrm{S}, 44^{\circ} 50^{\prime} \mathrm{W}\right)$ and contains subtropical hygroscopic forest (Barth, 1957).

We collected the flies on 28, 29 and 30 August 1987; 11, 12, 13 March and 26, 27, 28 November 1988. In August 1987 we took samples from five different altitudes: $700 \mathrm{~m}, 850 \mathrm{~m}, 970 \mathrm{~m}, 1020 \mathrm{~m}$ and $1300 \mathrm{~m}$.

Drosophila mediopunctata males were brought to the laboratory and individually crossed to three virgin females of a homokaryotypic strain of known genetic composition (ITC-229ET). Male gene arrangements in chromosomes II and $\mathrm{X}$ were determined by the analysis of up to eight $F_{1}$ larvae, ensuring that the probability of incorrect assignments was smaller than 1 per cent (Arnold, 1981). After crossing, 14 different body measurements were taken from each male as follows.

1 Thorax length ( $\mathrm{T}$ ): from the anterior margin of the thorax to the posterior tip of the scutellum.

2 Femur length (FE).

3 Tibia length (TB).

4 Eleven measurements between landmarks of the wing $(\mathrm{OA}, \mathrm{OB}, \mathrm{OE}, \mathrm{AB}, \mathrm{AE}, \mathrm{BC}, \mathrm{BD}, \mathrm{BE}, \mathrm{CD}, \mathrm{CE}$ and DE; Fig. 1). These distances were chosen according to the truss box method (see Bookstein et al., 1985 for detailed description and discussion).

We measured the thorax length under a stereomicroscope with an ocular micrometer. The right hind leg and the right wing were dissected and mounted on a slide in water and their landmarks were drawn using a camera lucida attached to a microscope. The Cartesian coordinates of the landmarks were then taken using a digitalizing pad connected to an AT microcomputer. This procedure allowed us to calculate the distances between any points. All the measurements were taken by the same person. Thorax length was measured in $1 / 40 \mathrm{~mm}$ units and leg and wing distances in $1 / 60 \mathrm{~mm}$ units.

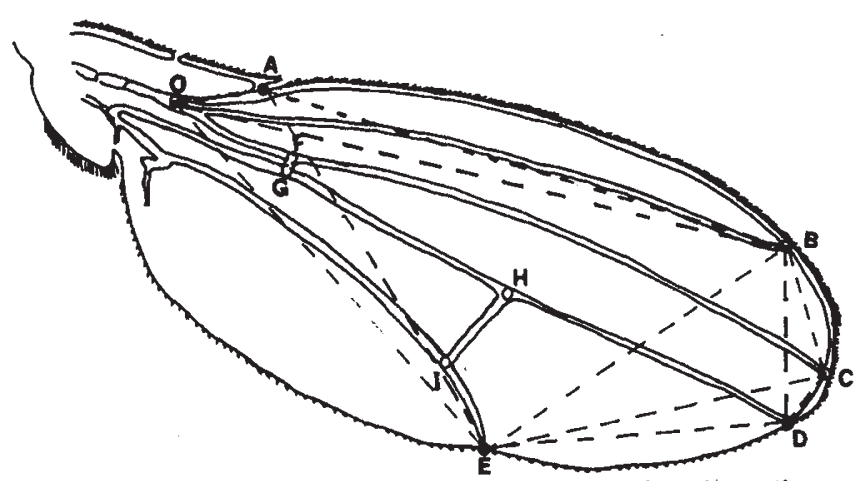

Fig. 1 Diagrammatic representation of the right wing. The truss network of distance measures was applied to six landmarks. The distances $\mathrm{OA}, \mathrm{OB}, \mathrm{OE}, \mathrm{AB}, \mathrm{AE}, \mathrm{BC}, \mathrm{BD}, \mathrm{BE}$, $\mathrm{CD}, \mathrm{CE}$ and $\mathrm{DE}$ were taken.

(c) The Genetical Society of Great Britain, Heredity, 75, 54-61. 
Statistical procedures utilized the sAs computer package (SAS Institute 1988). The principal components analysis (PCA), employing the correlation matrix, was used to generate a reduced set of orthogonal vectors from log-transformed original variables.

Two sets of principal components analyses of all characters for $D$. mediopunctata males were carried out. The first analysis included only data obtained from the August 1987 (PCA-A) collections. The second analysis dealt with data from collections from all three months (PCA-T).

\section{Results}

\section{Altitudinal variation}

The analysis of the data from August shows that the first two principal components (PC1-A and PC2-A) account for 80 and 6 per cent of the total variation, respectively. $\mathrm{PC} 1-\mathrm{A}$ is highly correlated with all variables (Fig. 2a), indicating that it is a good measure of size. PC2-A is a measure of shape and is primarily influenced by the distances $\mathrm{BC}$ and $\mathrm{BD}$, to which it is highly correlated.
Table 2 shows, for each measurement and PC1-A and PC2-A, the means and correlations with altitude. All of the measurements of the distal quadrilateral of the wing $(\mathrm{BC}, \mathrm{BD}, \mathrm{BE}, \mathrm{CD}, \mathrm{CE}$ and $\mathrm{DE})$ showed a significant correlation with altitude, while none of the remaining measurements showed a detectable correlation with altitude. This translates to a significant correlation for shape (PC2-A) but not for size (PC1-A). However, even for $\mathrm{BD}$ (which gives the largest coefficient of correlation, $r=0.25$ ), only a small part of its variation can be explained by the altitude variation (approximately 6 per cent).

\section{Temporal changes and effects of chromosome inversions}

When data from all flies collected were analysed the first two principal components (PC1-T and PC2-T) accounted for 78 and 7 per cent of the total variation as with the August data. PC1-T can be interpreted as variation in size and PC2-T (shape) represents, primarily, variations in the distances $\mathrm{BC}$ and $\mathrm{BD}$. To avoid intramonth correlation between PC1-T and PC2-T we carried out a shear transformation on PC2-T

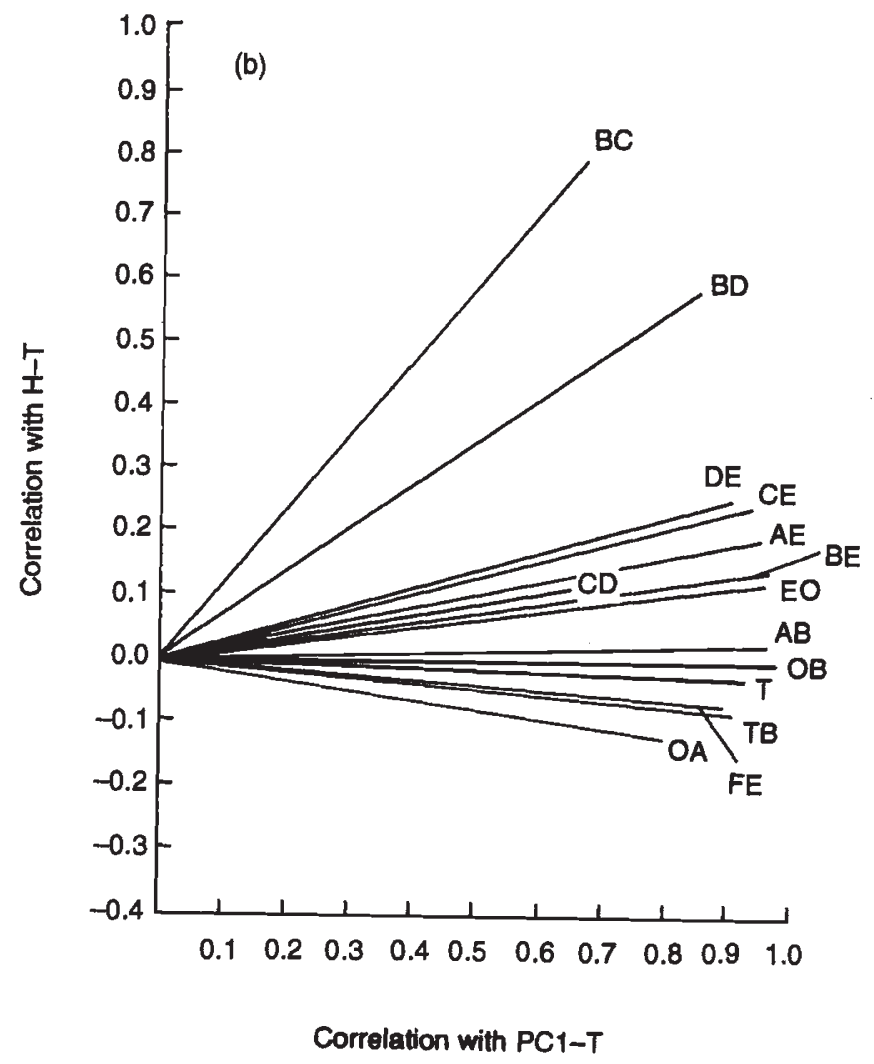

Correlation with PC1-T

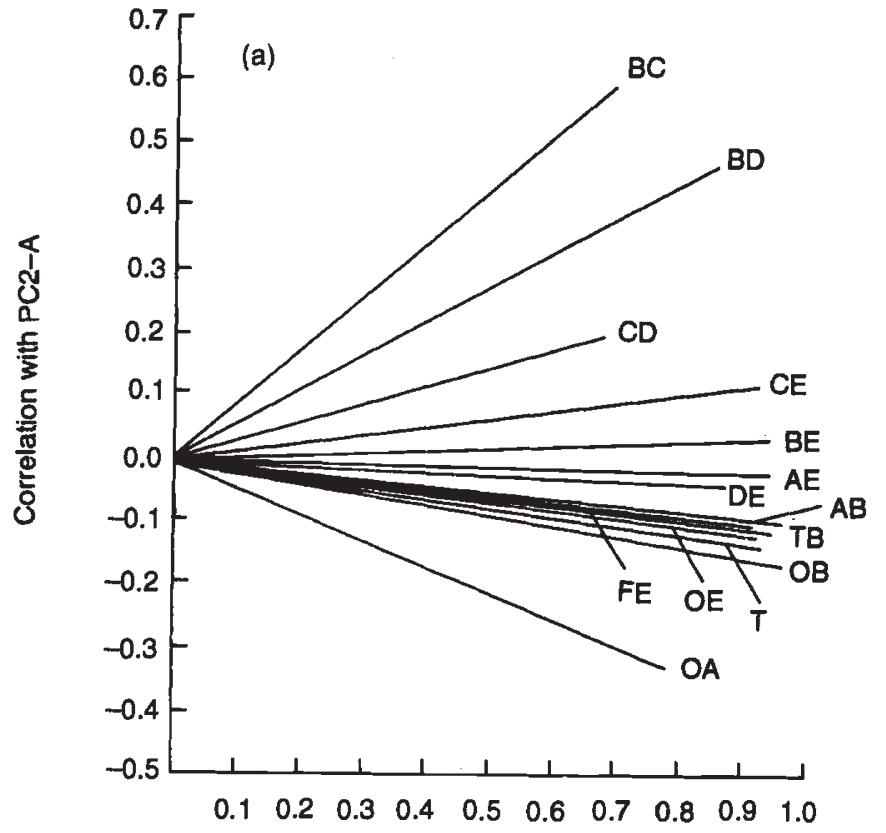

Correlation with PC1-A

Fig. 2 Corresponding correlations of each character with the first two principal components of correlation matrices. (a) Male sample from August 1987, (b) pooled males collected in August 1987, March 1988 and November 1988. Vectors indicate the direction of maximum variation for each character within the principal components plane. 
Table 2 Means $( \pm \mathrm{SE})$ of each character and of PC1-A and PC2-A, by altitude, for Drosophila mediopunctata males collected in August 1987

\begin{tabular}{lcccccc}
\hline \multicolumn{5}{c}{ Altitude $(\mathrm{m})$} \\
\cline { 2 - 6 } Character & $\begin{array}{c}\text { 1300 } \\
(n=6)\end{array}$ & $\begin{array}{c}1020 \\
(n=15)\end{array}$ & $\begin{array}{c}970 \\
(n=38)\end{array}$ & $\begin{array}{c}850 \\
(n=36)\end{array}$ & $\begin{array}{c}700 \\
(n=35)\end{array}$ & $r$ \\
\hline T & $58.0 \pm 1.0$ & $58.5 \pm 1.1$ & $56.4 \pm 0.8$ & $55.6 \pm 0.7$ & $56.4 \pm 0.6$ & 0.11 \\
FE & $50.5 \pm 0.6$ & $50.8 \pm 0.9$ & $49.2 \pm 0.7$ & $48.7 \pm 0.6$ & $49.1 \pm 0.5$ & 0.12 \\
TB & $54.5 \pm 0.8$ & $55.5 \pm 1.0$ & $52.9 \pm 0.8$ & $52.1 \pm 0.7$ & $53.1 \pm 0.5$ & 0.12 \\
OA & $27.9 \pm 0.8$ & $29.2 \pm 0.6$ & $27.8 \pm 0.4$ & $27.5 \pm 0.4$ & $27.6 \pm 0.4$ & 0.11 \\
OB & $146.0 \pm 0.8$ & $147.1 \pm 2.8$ & $143.9 \pm 1.9$ & $140.9 \pm 1.8$ & $142.0 \pm 1.3$ & 0.15 \\
OE & $110.2 \pm 1.5$ & $112.5 \pm 2.5$ & $109.1 \pm 1.3$ & $107.2 \pm 1.4$ & $107.9 \pm 1.1$ & 0.14 \\
AB & $119.9 \pm 0.6$ & $119.7 \pm 2.4$ & $117.7 \pm 1.6$ & $114.9 \pm 1.4$ & $116.0 \pm 1.1$ & 0.16 \\
AE & $94.7 \pm 1.1$ & $96.0 \pm 2.3$ & $92.9 \pm 1.1$ & $91.1 \pm 1.1$ & $91.9 \pm 0.9$ & 0.16 \\
BC & $30.5 \pm 0.7$ & $30.2 \pm 0.6$ & $29.9 \pm 0.4$ & $29.2 \pm 0.4$ & $28.9 \pm 0.4$ & $0.22^{*}$ \\
BD & $39.1 \pm 0.6$ & $38.8 \pm 0.7$ & $38.4 \pm 0.5$ & $37.1 \pm 0.4$ & $37.0 \pm 0.4$ & $0.25^{* *}$ \\
BE & $77.4 \pm 0.8$ & $77.4 \pm 1.4$ & $75.5 \pm 1.1$ & $73.4 \pm 0.8$ & $73.8 \pm 0.7$ & $0.22^{* *}$ \\
CD & $15.7 \pm 1.1$ & $14.9 \pm 0.3$ & $15.1 \pm 0.3$ & $14.3 \pm 0.3$ & $14.4 \pm 0.3$ & $0.21^{*}$ \\
CE & $77.9 \pm 0.8$ & $77.7 \pm 1.3$ & $76.6 \pm 1.0$ & $74.1 \pm 0.8$ & $74.6 \pm 0.7$ & $0.23^{* *}$ \\
DE & $65.5 \pm 1.1$ & $66.3 \pm 1.1$ & $64.9 \pm 0.9$ & $63.1 \pm 0.6$ & $63.5 \pm 0.6$ & $0.19^{*}$ \\
PC1-A & $0.42 \pm 0.07$ & $0.47 \pm 0.27$ & $0.10 \pm 0.19$ & $-0.12 \pm 0.13$ & $-0.23 \pm 0.18$ & 0.17 \\
PC2-A & $0.43 \pm 0.35$ & $-0.12 \pm 0.18$ & $0.32 \pm 0.14$ & $-0.30 \pm 0.20$ & $-0.08 \pm 0.17$ & $0.20^{*}$ \\
\hline
\end{tabular}

$n$, number of flies analysed; $r$, correlation with altitude.

${ }^{*} P \leqslant 0.05,{ }^{* *} P \leqslant 0.01$.

obtaining H-T (this technique is discussed by Bookstein et al., 1985). Figure 2(b) shows the correlation between each of the measurements with PC1-T and H-T. Again, the results are very similar to those obtained from the August data (Fig. 2a).

To test whether the differences among months and among karyotypes of chromosome II inversions were statistically significant we performed a two-way analysis of variance, with interaction between month and karyotypes, for each of the measurements as well as for PC1-T and H-T.

Since there were many possible karyotypes and some of them were very rare, they were pooled before carrying out the analysis. For chromosome II, we formed five classes:

1 the commonest homokaryotype $(D A-P A O / D A$ $P A O)$;

2 the commonest heterokaryotype ( $D A-P A O / D I-P B O)$; 3 the heterokaryotypes between $D A-P A O$ and reasonably frequent haplotypes (i.e. frequency $>1$ per cent in all months) (DS-PCO,DP-PCO,DV-PCO and $D T-P C 1$ );

4 homokaryotypes and heterokaryotypes formed by the reasonably frequent haplotypes; and

5 karyotypes that had one rare combination (e.g. $D A$ $P B O)$ or rare arrangement (e.g. $D A-P A B)$.

The ANOva results are shown in Table 3. The means per month, per karyotype, are given for PC1-T in Table 4 and for $\mathrm{H}-\mathrm{T}$ in Table 5.
Table 3 Results of the two-way ANOvas for differences among months, karyotypes of Drosophila mediopunctata and their interaction on the characters analysed, PC1-T and H-T

\begin{tabular}{lcll}
\hline Character & $\begin{array}{c}\text { Month } \\
F_{2,230}\end{array}$ & $\begin{array}{c}\text { Karyotype } \\
F_{4,230}\end{array}$ & $\begin{array}{c}\text { Interaction } \\
F_{8,230}\end{array}$ \\
\hline T & $17.13^{* * *}$ & 0.92 & $3.07^{* *}$ \\
FE & $6.75^{* *}$ & 0.93 & $2.44^{*}$ \\
TB & $8.23^{* * *}$ & 0.61 & $2.12^{*}$ \\
OA & $3.49^{*}$ & 0.40 & 1.65 \\
OB & $15.30^{* * *}$ & 0.91 & $2.52^{*}$ \\
OE & $25.17^{* * *}$ & 1.96 & $2.13^{*}$ \\
AB & $18.08^{* * *}$ & 1.06 & $2.51^{*}$ \\
AE & $30.44^{* * *}$ & 2.24 & $2.05^{*}$ \\
BC & $45.63^{* * *}$ & $4.87^{* * *}$ & 1.53 \\
BD & $32.46^{* * *}$ & $3.10^{*}$ & 1.07 \\
BE & $16.18^{* * *}$ & 0.87 & $2.36^{*}$ \\
CD & $5.10^{* *}$ & 0.85 & 1.06 \\
CE & $23.86^{* * *}$ & 1.28 & $2.62^{* *}$ \\
DE & $24.59^{* * *}$ & 1.13 & $3.18^{* *}$ \\
PC1-T & $21.93^{* * *}$ & 1.31 & $2.67^{* *}$ \\
H-T & $30.54^{* * *}$ & $4.22^{* *}$ & 0.55 \\
\hline
\end{tabular}

${ }^{*} P \leqslant 0.05,{ }^{* *} P \leqslant 0.01,{ }^{* * *} P \leqslant 0.001$.

For all characters there was a significant month effect that can be attributed to differences in size and shape. The last column of Table 4 shows the means per month of PC1-T (size) and the result of the Tukey test: flies collected in March are significantly smaller than 
those collected in August or November. For shape (H$\mathrm{T})$ the flies from the three months showed different means (Table 5). These differences in size and shape are shown in Fig. 3.

Only for BC and BD was the effect of the karyotype significant at the 0.05 level. However, for all measures - except OA, BC, BD and CD - a significant interaction was found between karyotype and month. These results are reflected first in PC1-T (size) which, in spite of having no significant karyotype effect, does show a significant karyotype $\times$ month interaction. This interaction is easy to see in Fig. 4, where the same karyotype (e.g. IV) may either be the largest or the smallest depending on the collecting month (March or November). In addition, the karyotype directly influences shape. The mean of group $\mathrm{V}$ is significantly different from those of groups I and II (Table 5).

For chromosome $\mathrm{X}$ we could not detect any inversion effect nor any interaction between inversion $\times$ month on the isolated characters, nor on the components obtained, or in a multifactorial analysis (MANOVA; Wilk's Lambda for genotypes: 0.88; d.f. $=28$, 446; $P=0.328$; Wilk's Lambda for interaction: 0.79 ; d.f. $=56,869 ; P=0.502$ ).

\section{Discussion}

The results obtained offer a picture of the major dimensions of morphometric variation in a natural population of Drosophila mediopunctata. The same pattern was observed both in the variation within a single month (PCA-A) and among months (PCA-T). 'General size' accounts for most of the variation: approximately 80 per cent. The second major source of variation represents, primarily, the contrast between $\mathrm{BC}$ and $\mathrm{BD}$ distances against other distances.

Since our results are highly influenced by wing measures (11 out of a total of 14), they compare best with studies that use only wing measurements. Studies of laboratory populations of $D$. melanogaster have yielded similar results. In respect of temperature effects, Alonso \& Munoz (1984), using two groups maintained at $25^{\circ} \mathrm{C}$ and $30^{\circ} \mathrm{C}$, observed that although the second principal component essentially contrasted the distance $A B$ (length) against $B D$ and $C D$, the distance $B C$ was not useful in indicating either size or form variation. Cavicchi et al. (1978) performed an experiment on laboratory strains of D. melanogaster where one sample was maintained at $25{ }^{\circ} \mathrm{C}$ and the other at $28^{\circ} \mathrm{C}$. Nine dimensional characters of the wing were measured over six generations and the differences between the mean values were computed. They were different from zero for all characters, with the exception of BC and BD. We observed (Klaczko \& BitnerMathé, 1990) that Drosophila's wings can be accurately described by an ellipse. We used this geometrical figure to compare variations in size and shape between wild-caught $D$. mediopunctata and their

Table 4 Mean PC1-T, standard error (SE) and sample size $(n)$ by months and chromosome II karyotypes for total males of Drosophila mediopunctata collected

\begin{tabular}{lcccccc}
\hline & \multicolumn{5}{c}{ Karyotype } & \\
\cline { 2 - 5 } Month & I & II & III & IV & V & Total \\
\hline August & & & & & & \\
$\quad$ Mean & 2.13 & 0.26 & 0.94 & 1.14 & -0.27 & $0.93^{\text {a }}$ \\
SE & 0.48 & 0.57 & 0.56 & 0.82 & 0.71 & 0.27 \\
$n$ & 32 & 30 & 33 & 17 & 18 & 130 \\
March & & & & & & \\
Mean & -2.93 & -0.10 & -2.16 & -4.33 & -0.45 & $-2.21^{\text {b }}$ \\
SE & 0.81 & 1.24 & 0.82 & 1.12 & 0.70 & 0.45 \\
$n$ & 11 & 7 & 17 & 12 & 10 & 57 \\
November & & & & & & \\
Mean & 0.52 & -1.32 & -0.08 & 0.90 & -0.64 & $0.08^{\text {a }}$ \\
SE & 0.72 & 1.57 & 0.62 & 0.46 & 0.88 & 0.34 \\
$n$ & 12 & 7 & 17 & 15 & 7 & 58 \\
Total & & & & & & \\
$\quad$ Mean & 0.77 & -0.05 & -0.11 & -0.44 & -0.40 & \\
SE & 0.44 & 0.49 & 0.41 & 0.58 & 0.44 & \\
$n$ & 55 & 44 & 67 & 44 & 35 & \\
\hline
\end{tabular}

The Tukey test was used for contrasts among months and among karyotypes.

Means with the same superscript are not significantly different. 
Table 5 Mean H-T, standard error (SE) and sample size $(n)$ by months and chromosome II karyotypes for total males of Drosophila mediopunctata collected

\begin{tabular}{|c|c|c|c|c|c|c|}
\hline \multirow[b]{2}{*}{ Month } & \multicolumn{5}{|c|}{ Karyotype } & \multirow[b]{2}{*}{ Total } \\
\hline & I & II & III & IV & V & \\
\hline \multicolumn{7}{|l|}{ August } \\
\hline Mean & 0.68 & 0.41 & 0.28 & 0.51 & -0.11 & $0.39^{\mathrm{a}}$ \\
\hline SE & 0.14 & 0.16 & 0.16 & 0.15 & 0.15 & 0.07 \\
\hline$n$ & 32 & 30 & 33 & 17 & 18 & 130 \\
\hline \multicolumn{7}{|l|}{ March } \\
\hline Mean & -0.35 & -1.00 & -0.61 & -0.71 & -0.86 & $-0.67^{b}$ \\
\hline $\mathrm{SE}$ & 0.18 & 0.32 & 0.30 & 0.36 & 0.25 & 0.14 \\
\hline$n$ & 11 & 7 & 17 & 12 & 10 & 57 \\
\hline \multicolumn{7}{|l|}{ November } \\
\hline Mean & -0.37 & 0.31 & -0.12 & -0.06 & -0.94 & $-0.20^{\mathrm{c}}$ \\
\hline $\mathrm{SE}$ & 0.26 & 0.46 & 0.16 & 0.23 & 0.35 & 0.12 \\
\hline$n$ & 12 & 7 & 17 & 15 & 7 & 58 \\
\hline \multicolumn{7}{|l|}{ Total } \\
\hline Mean & $0.25^{\mathrm{a}}$ & $0.17^{\mathrm{a}}$ & $-0.05^{\mathrm{ab}}$ & $-0.02^{\mathrm{ab}}$ & $-0.49^{b}$ & \\
\hline SE & 0.13 & 0.16 & 0.12 & 0.15 & 0.14 & \\
\hline$n$ & 55 & 44 & 67 & 44 & 35 & \\
\hline
\end{tabular}

The Tukey test was used for contrasts among months and among karyotypes. Means with the same superscript are not significantly different.

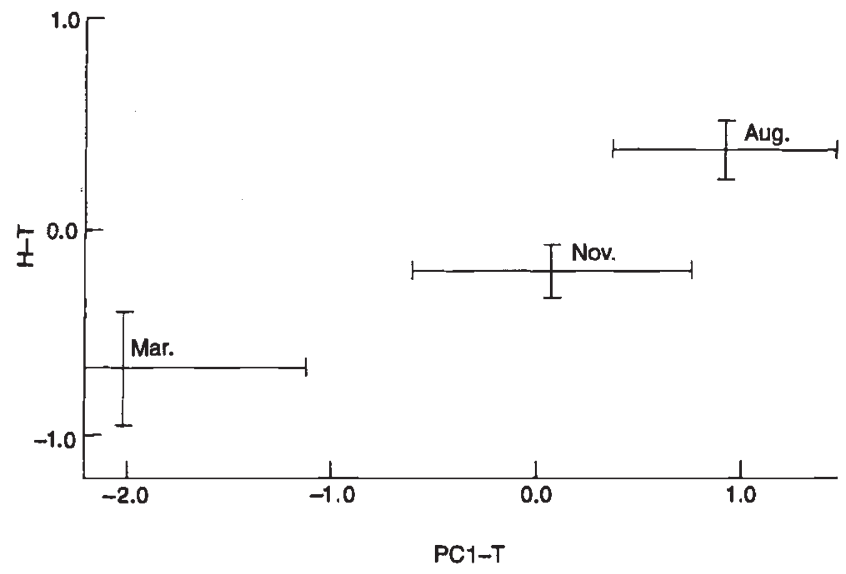

Fig. 3 The months' average scores on the first two principal components of all characters. Sheared component II was used (H-T). Axis units are arbitrary and each bar represents two standard errors.

daughters raised in the laboratory at two different temperatures. Clear differences in size (inversely correlated with temperature) were found between these three populations. However, no significant variation in wing shape was detected. Unpublished data from this same study showed that although there are no differ-

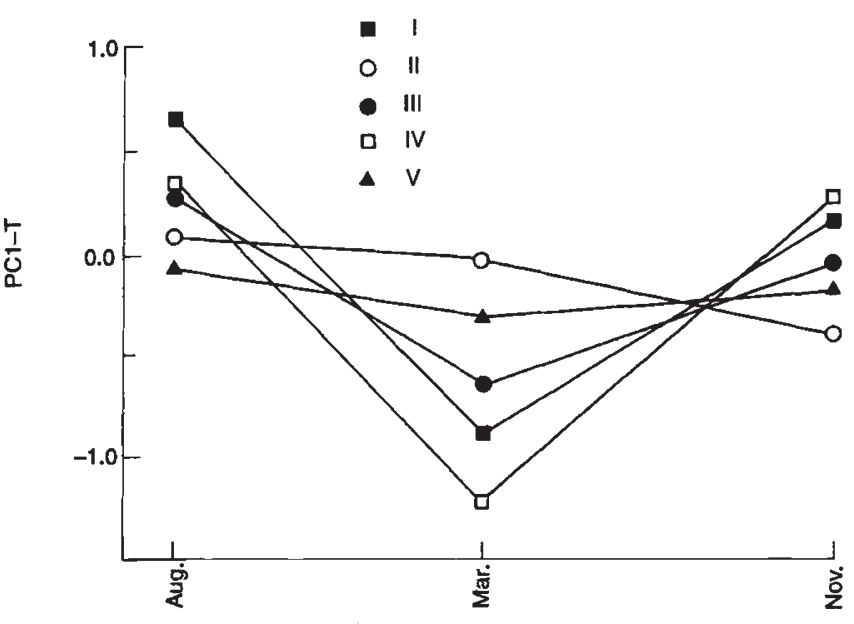

Fig. 4 Mean score on PC1-T ('general size') for the five second chromosome karyotype groups among wild males plotted for three months. Each line represents a different karyotype group (see Material and methods). PC1-T axis units are arbitrary. I, $D A-P A O / D A-P A O ; \mathrm{II}, D A-P A O /$ $D I-P B O$; III, the heterokaryotypes between $D A-P A O$ and haplotypes which were mildly frequent $(D S-P C O, D P-P C O$, $D V-P C O$ and $D T-P C 1$ ); IV, the homokaryotypes and heterokaryotypes formed by the mildly frequent haplotypes; $\mathrm{V}$, the karyotypes that contained rare haplotypes (for example $D A$ $P B 0$ or $D A-P A 8)$. 
ences in the overall outline of the wing, there is significant variation in the position of point $B$ between the wild-caught flies and laboratory-reared ones, but no such difference between the two laboratory groups kept at different temperatures. The influence of temperature changes on size variation has been extensively cited (Tantawy, 1964; Coyne \& Beecham, 1987). The shape variation (independent of size) present between altitudes and months may reflect changes in the placement of the wing veins and not necessarily changes in its outline.

Analysing the effect of chromosomal inversions, we observe only the direct effect of chromosome II inversions on the distances BC and BD. Group V, which accounts for haplotypes with rare inversion combinations (NB - there is a strong linkage disequilibrium between the proximal and distal regions), showed significant differences. This may perhaps indicate that these rare 'recombinants' are not very well coadapted.

With regard to size, which accounts for the largest part of the morphological variation, we did not detect any overall differences among karyotypes. However, we found overall differences between collecting dates and a strong interaction between karyotype and collecting date. In recent work with $D$. melanogaster, David et al. (1994) demonstrated different reaction norms of size characters in relation to growth temperature among 10 genetically different isofemale lines. Santos et al. (1994) showed clear evidence of gene-environment interaction for the effect of body size on fitness.

In our case, it is not possible to identify clearly what is happening because some of the groups we formed were very heterogeneous. However, groups I and II, which are homogeneous $(D A-P A O / D A-P A O$ and $D A$ $P A 0 / D I-P B 0$, respectively), do show typical interactive behaviour (see Fig. 4). Lewontin (1974) stressed the importance of genotype-environment interaction and pointed out the erroneous conclusions that might be drawn if the interaction is ignored, particularly for estimates of heritability. Our results resemble figure 4. 1. b of his paper, if we assume that collecting date is a continuous environmental variable. There is an overall environment effect (flies collected in March are smallest) but no overall genotypic effect, because of the genotype-environment interaction.

As Lewontin (1974) remarked 'evidence on actual norms of reaction is very hard to come by', even though there are papers documenting the existence of genotype-environment interaction (see for example, for life-history traits: Tachida \& Mukay, 1985; Etges, 1989; Van Delden \& Kamping, 1991; and references cited by Lewontin, 1974). "This relative lack of empirical evidence for interactions' has led Sesardic (1993) to claim that norm of reaction is a misleading concept, although he conceded that it 'may be due to difficulties in designing the tests that could detect them'. Moreover, Sesardic criticized the traditional view of norm of reaction, where a genotype had to be tested in all possible environments, as a 'curious triumph of the possible over the actual'. Our results clearly show the presence of an actual genotype-environment interaction under natural conditions for the largest component of morphological variation. Moreover, they point to the necessity of studying reaction norms to understand the biological meaning of inversion chromosome polymorphisms.

\section{Acknowledgments}

We are grateful to Luis Lima Neto who provided us with the digitizing pad software, Dr Sergio Reis for invaluable suggestions during the development of this work and help with computation facilities and $\mathrm{Dr}$ Richard Strauss for insightful comments on the shearing method. We also thank Dr Antonio Bernardo de Carvalho, Dr Carlos R. Vilela and anonymous reviewers for critical comments of this manuscript. Mrs Cléa Knauer da Silva gave us technical assistance. The Núcleo de Computação Gráfica da COPPE and NUTES from Universidade Federal do Rio de Janeiro provided facilities to perform part of this work. These investigations were supported by: Conselho Nacional de Desenvolvimento Científico e Tecnológico ( $\mathrm{CNPq})$; Financiadora de Estudos e Projetos (FINEP); Coordenação de Aperfeicoamento de Pessoal de Ensino Superior (CAPES) and Fundação de Amparo à Pesquisa do Rio de Janeiro (FAPERJ).

\section{References}

ALONSO, A. AND MUNOZ, A. 1984. Biometric characterization of some wing measurements in Drosophila melanogaster. Drosoph. Inf. Serv., 60, 47-48.

ARNOLD, J. 1981. Statistics of natural populations. I: Estimating an allele probability in cryptic fathers with a fixed number of offspring. Biometrics, 37, 495-504.

BARTH, R. 1957. A fauna do Parque Nacional do Itatiaia. Bol. Pq. Nac. Itatiaia, no. 6, 150 pp. Serviço Florestal, Ministério da Agricultura, Resende, Rio de Janeiro.

BOOKSTEIN, F. L., CHERNOFF, B., ELDER, R. L., HUMPHRIES, J. M., SMITH, G. R. AND STRAUSS, R. E. 1985. Morphometrics in Evolutionary Biology. Academy of Natural Sciences, Philadelphia, PA.

CAVICCHI, S., GIORGI, G. AND MOCHI, M. 1978. Investigation on early divergence between populations of Drosophila melanogaster kept at different temperatures. Genetica, 48, $81-87$.

COYNE, J. A. AND BEECHAM, E. 1987. Heritability of two morphological characters within and among natural populations of Drosophila melanogaster. Genetics, 117, 727-737.

(c) The Genetical Society of Great Britain, Heredity, 75, 54-61. 
DAVID, J. AND BOCQUET, C. 1975. Similarities and differences in latitudinal adaptation of two Drosophila sibling species. Nature, 257, 588-590.

DAVID, J, R., MORETEAU, B., GAUTHIER, J. P., PÉtAVY, G., TOCKEL, A. AND IMASHEVA, A. G. 1994. Reaction norms of size characters in relation to growth temperature in Drosophila melanogaster: an isofemale lines analysis. Génét. Sél. Évol., 26, 229-251.

ETGES, w. J. 1989. Chromosomal influences on life-history variation along an altitudinal transect in Drosophila robusta. Am. Nat., 133, 83-110.

GARCIA-VAZQUEZ, E. AND SÁNCHEZ-REFUSTA, F. 1989. Chromosomal polymorphism and extra bristles of Drosophila melanogaster: joint variation under selection in isofemale lines. Genetica, 78, 91-96.

HASSON, E., FANARA, J. J., RODRIGUEZ, C., VILARDI, J. C., REIG, O. A. AND FONTDEvila, A. 1992. The evolutionary history of Drosophila buzzatii. XXIV. Second chromosome inversions have different average effects on thorax length. Heredity, 68, 557-563.

IMASHEVA, A. G., BUBLI, O. A. AND LAZEBNY, O. E. 1994. Variation in wing length in Eurasian natural populations of Drosophila melanogaster. Heredity, 72, 508-514.

KLACZKo, L. B. AND BITNER-MATHE, B. C. 1990 . On the edge of a wing. Nature, 346, 231.

KRIMBAS, C. B. AND POWELL, J. R. 1992. Drosophila Inversion Polymorphism. CRC Press, Boca Raton, FL.

LEWONTIN, R. C. 1974. The analysis of variance and the analysis of causes. Am. J. Hum. Genet., 26, 400-411.

MARCUS, L. F. 1990. Traditional morphometrics. In: Rohlf, F. J. and Bookstein, F. L. (eds) Proc. Michigan Morphometric Workshop. Special Publication Number 2, pp. 77-122. The University of Michigan Museum of Zoology, Ann Arbor, MI.

MATZKE, M. M. AND DRUGER, M. 1976. Evolutionary divergence between two populations of Drosophila pseudoobscura. Evolution, 31, 597-602.

MAYNARD SMITH, J., BURIAN, R., KAUFFMAN, S., ALBERCH, P., CAMPBELL, J., GOODWIN, B., LANDE, R., RAUP, D. AND WOLPERT, L. 1985. Developmental constraints and evolution. Q. Rev. Biol., 60, 265-287.

MISRA, R. K. 1966. Vectorial analysis for genetic clines in body dimensions in populations of Drosophila subobscura Coll. and a comparison with those of Drosophila robusta Sturt. Biometrics, 22, 469-487.

MISRA, R. K. AND REEVE, E. C. R. 1964. Clines in body dimensions in populations of Drosophila subobscura. Genet. Res., 5, 240-256.

PEIXOTO, A. A. AND KLACZKo, L. в. 1988. Polimorfismos de inversões cromossômicas em Drosophila mediopunctata III. Variacões sazonal e microgeográfica. Cienc. Cult., 40(Suppl.), 770.

PEIXOTO, A. A. AND KLACZKo, L. в. 1991. Linkage disequilibrium analysis of chromosomal inversion polymorphisms of Drosophila. Genetics, 129, 773-777.

PFRIEM, P. 1983. Latitudinal variation in wing size in Drosophila subobscura and its dependence on polygenes of chromosome O. Genetica, 61, 221-232.

PREVOSTI, A. 1955. Geographical variability in quantitative traits in populations of Drosophila subobscura. Cold Spring Harb. Symp. Quant. Biol., XX, 294-299.

PRICE, T. AND LANGEN, T. 1992. Evolution of correlated characters. Trends Ecol. Evol., 7, 307-310.

PROUT, T. AND BARKER, J. S. F. 1989. Ecological aspects of the heritability of body size in Drosophila buzzatii. Genetics, 123, 803-813.

RUIZ, A., SANTOS, M., BARBADILLA, A., QUEZADA-DAZ, J. E., HASSON, E. AND FONTDEVILA, A. 1991. Genetic variance for body size in a natural population of Drosophila buzzatii. Genetics, 128, 739-750.

SANTOS, M., FOWLER, K. AND PARTRIDGE, L. 1994. Gene-environment interaction for body size and larval density in Drosophila melanogaster: an investigation of effects on development time, thorax length and adult sex ratio. Heredity, 72, 515-521.

SAS INSTITUTE 1988. SAS/STAT User's Guide, Release 6.03 Edition. SAS Institute, Cary, NC.

SESARdic, N. 1993. Heritability and causality. Phil. Sci., 60, 396-418.

SOKOLOFF, A. 1965. Geographic variation of quantitative characters in populations of Drosophila pseudoobscura. Evolution, 19, 300-310.

SPERLICH, D. AND PFRIEM, P. 1986. Chromosomal polymorphism in natural and experimental populations. In: Ashburner, M., Carson, H. L. and Thompson, J. N., Jr. (eds) The Genetics and Biology of Drosophila, vol. 3e, pp. 257-309. Academic Press, London.

STALKER, H. D. AND CARSON, H. L. 1947. Morphological variation in natural populations of Drosophila robusta Sturtevant. Evolution, 1, 237-248.

STALKER, H. D. AND CARSON, H. L. 1948. An altitudinal transect of Drosophila robusta Sturtevant. Evolution, 2, 295-305.

STALKER, H. D. AND CARSON, H. L. 1949. Seasonal variation in the morphology of Drosophila robusta. Evolution, 3, 330-343.

TACHIDA, H. AND MUKAI, T. 1985. The genetic structure of natural populations of Drosophila melanogaster. XIX. Genotype-environment interaction in viability. Genetics, 111, 43-55.

TANTAWY, A. O. 1964. Studies on natural populations of Drosophila. III. Morphological and genetic differences of wing length in Drosophila melanogaster and D. simulans in relation to season. Evolution, 18, 560-570.

VAN DELDEN, W. AND KAMPING, A. 1991. Changes in relative fitness with temperature among second chromosome arrangements in Drosophila melanogaster. Genetics, 127, 507-514. 